\title{
Rare injury - acetabular fracture combined with ipsilateral intertrochanteric fracture: treatment and outcome in patients with at least 6 years of follow-
}

up

Bo Liu

Hebei Medical University Third Affiliated Hospital

Wenhui Ma

Hebei Medical University Third Affiliated Hospital

Sikai Liu

Hebei Medical University Third Affiliated Hospital

Xiao Chen

Hebei Medical University Third Affiliated Hospital

Mengnan Li

Hebei Medical University Third Affiliated Hospital

Jia Huo

Hebei Medical University Third Affiliated Hospital

Huijie Li

Hebei Medical University Third Affiliated Hospital

Yongtai Han ( $\nabla$ yongtaihan@foxmail.com )

Hebei Medical University Third Affiliated Hospital

Research article

Keywords: fracture; dislocation; acetabulum; intertrochanteric fracture

Posted Date: May 8th, 2020

DOI: https://doi.org/10.21203/rs.3.rs-25681/v1

License: (c) (i) This work is licensed under a Creative Commons Attribution 4.0 International License.

Read Full License 


\section{Abstract \\ Background}

Fractures involving both the acetabulum and the ipsilateral femoral trochanter are rarely reported. The aims of our study were to identify the etiological characteristics, summarize the treatment methods, and analyze the mid- to long-term prognosis for this kind of rare injury.

\section{Methods}

A total of 18 patients who were treated in our hospital for a combination of ipsilateral acetabular fracture and intertrochanteric fracture from 2003 to 2013 was retrospectively analyzed. The etiology, fracture classifications, treatment and prognosis of patients were identified.

\section{Results}

We followed up with patients for 6.2 years to 16 years. In this study, injuries occurred most commonly via traffic accidents, followed by falls from a tall height and crushing injury. Six patients had posterior dislocation of the hip joint. Evans type 3 fracture and Letournel type 1 fracture were the most common fractures among these patients. All patients received internal fixation for their intertrochanteric fracture. Some patients also received internal fixation for their acetabular fracture. However, for the other patients, acetabular fractures were treated conservatively or with fracture fragment resection. One elderly (87 years) female patient had pulmonary disease and died at 24 days postoperatively. In other patients, fractures all achieved bony healing. Twelve patients achieved excellent and good results (Harris score $\geq$ 80 points), and 5 patients achieved fair and poor results (Harris score $<80$ points). The proportion of patients who achieved an excellent-good Harris score was $70.6 \%$. Dislocation of the hip was found to be an independent risk factor $(\mathrm{HR}=9.194,95 \% \mathrm{Cl}=1.024-82.515)$ for poor patient outcomes.

\section{Conclusion}

The detailed characteristics of patients with acetabular fracture and ipsilateral intertrochanteric fracture were identified in this study. For patients who undergo surgical treatment, fracture healing is usually achieved. However, the occurrence of complications, especially avascular necrosis, is the major cause of poor prognosis. Dislocation of the hip joint at the time of injury is considered to be an important risk factor for poor prognosis.

\section{Background}

An acetabular fracture is considered a serious injury and is usually caused by high-impact trauma[1, 2], such as a car accident or a fall from a tall height. In some cases, an acetabular fracture may coincide 
with a fracture of the proximal femur (and together with a dislocation of the hip joint). A so-called dashboard injury[3] includes a fractured posterior wall of the acetabulum with or without anatomical insult to the proximal femur. Based on the anatomy site of a proximal femoral fracture, these fractures could be divided into three subgroups: fractures involving the acetabulum and femoral head, femoral neck and femoral trochanter. The first two kinds of fractures might be more common because there have been some reports about them[4-8]. Several reports[3, 7] about intra-articular femoral head fracture associated with fracture-dislocation of the hip and acetabulum have been found. Additionally, ipsilateral fracture of the femoral neck associated with fracture of the acetabulum is also frequently reported[4-8].

In contrast, fractures involving both the acetabulum and femoral trochanter are rarely reported. To date, only a few cases of acetabular fracture combined with ipsilateral intertrochanteric fracture have been reported[9-11]. In these reports, the etiology, management and prognosis of patients with acetabular fracture combined with ipsilateral intertrochanteric fracture were described. However, due to the limited sample size, the results might only reflect one or several aspects of the fracture characteristics. In this study, we examined a case series of 18 patients with acetabular fracture combined with ipsilateral intertrochanteric fracture. We followed up with all patients for at least 6 years. The aims of our study were to identify the etiological characteristics, summarize the treatment methods, and analyze the mid- to longterm prognosis for this kind of rare injury.

\section{Methods}

Study population

We retrospectively reviewed a total of 18 patients who were treated in our hospital for combined ipsilateral acetabular fracture and intertrochanteric fracture from 2003 to 2013 . The general information, etiology, and fracture classifications of patients were identified based on either radiological images or medical records. The Evans' classification system and Letournel classification system[3] were used to evaluate intertrochanteric fracture and acetabular fracture, respectively. This study was approved by the Institutional Review Board of the Third Hospital of Hebei Medical University and was conducted in accordance with the Declaration of Helsinki. As this was a retrospective study and all patient information was deidentified before analysis, informed consent was only required for patients whose radiological images would be published.

Treatments

All patients underwent surgical treatment for their fractures. All surgical treatments were performed electively when the hemodynamic status was stable. No emergency surgical treatment was performed. For some patients who had hip dislocation, reduction of the dislocated joint was performed simultaneously with surgical treatment of the fracture. No emergency reduction was performed. The surgical treatment was generally divided into two categories: surgical treatment for acetabular fracture and surgical treatment for intertrochanteric fracture. Some patients received surgical treatment for acetabular fracture, and some patients received conservative treatment. In this study, the surgical 
procedure for acetabular fractures included the removal of fracture fragments (resection) or open reduction and internal fixation (ORIF). As most acetabular fractures are posterior wall fractures (Letournel type 1), the Kocher-Langenbeck approach is most commonly performed. Additionally, the most commonly used internal fixation materials for the treatment of acetabular fractures were reconstruction plates and screws. In this study, all patients had received surgical treatment (internal fixation) for intertrochanteric fracture. The intertrochanteric fractures were reduced and fixed simultaneously with the same incision for acetabular fracture. In some cases, the intertrochanteric fractures were fixed with dynamic hip screws through a lateral approach or fixed with an intramedullary nail using a minimally invasive technique (closed reduction and internal fixation, CRIF), while the acetabular fractures were treated conservatively. Acetabular fracture combined with ipsilateral intertrochanteric fracture was a serious intra-articular injury, so patients were required to be non-weight-bearing for 4 weeks, followed by a gradual increase from partial weight bearing to full weight-bearing in 12 weeks after surgery to ensure safety.

\section{Outcomes}

Clinical outcomes were evaluated by Harris scores[12]. Pain was evaluated by the visual analog score (VAS score). Three kinds of complications were also recorded: heterotopic ossification (evaluated by Brooker grade[12]), posttraumatic arthritis (evaluated by Kellgren-Lawrence grade[12]) and avascular necrosis of the femoral head. These complications were commonly identified in our cases. If a patient was converted to total hip arthroplasty (THA), the time to THA and the Harris scores before THA were also recorded. A patient was considered to have poor outcomes if the Harris score was less than 80 points or if the patient was converted to THA.

\section{Statistical analysis}

Statistical analyses were performed using SPSS version 19.0 statistical software for Windows (IBM, Armonk, New York). Continuous variables were expressed as the mean \pm SD, and categorical variables were expressed as frequencies. Cox regression analyses were used to assess the association between potential risk factors and poor outcomes of patients. Due to the limited sample size, we first built univariable Cox regression models to find the potential risk factors. Then, a multivariable Cox regression model was built to find the independent risk factors for poor outcomes. A P-value less than 0.05 was considered to be significant.

\section{Results}

General information

A total of 18 patients were initially included in this study. The mean age of the patients was $42.77 \pm$ 17.74 years. There were 15 males and 3 females. Ten patients had injuries on the right side, and 8 had injuries on the left side. In this study, injuries occurred most commonly via traffic accidents. Falling from a tall height was the second most common cause of injury, followed by crushing injury. Only one elderly 
(87 years) female patient was injured by slipping and falling on the ground. Six patients had posterior dislocation of the hip joint. According to the Evans classification for intertrochanteric fracture, there was 1 patient with Evans type 2 fracture, 13 patients with Evans type 3 fracture and 4 patients with Evans type 4 fracture. The Letournel classification for acetabular fracture of patients was also identified in this study. Letournel type 1 fractures (posterior wall fracture) were the most common fractures among others, followed by Letournel type 4 fractures, Letournel type 7 fractures and Letournel type 2 fractures. All patients received surgical treatment, and the mean time to surgery was $8.72 \pm 5.37$ days. The follow-up time was 6.2 years to 16 years. Details of the patients' general information are shown in Table 1.

\section{Treatments}

The treatments generally included treatment for acetabular fractures and treatment for intertrochanteric fractures.

The acetabular fractures were treated with one of three regimens: conservative treatment (6/18), resection of fracture fragments (2/18), and open reduction and internal fixation (ORIF, 10/18). For patients undergoing open reduction and internal fixation, plates and screws were most commonly used for internal fixation, followed by only screw fixation. Nine of 12 patients received ORIF or resection treatment via the Kocher-Langenbeck approach. In addition, the ilioinguinal approach, Watson-Jones approach and Smith-Peterson approach were used for the other three patients (Table 2).

In this study, intertrochanteric fractures were treated by internal fixation. Twelve of the eighteen intertrochanteric fractures were reduced and fixed via the same incision for acetabular fracture, 2/18 were reduced and fixed via the lateral approach, and 4/18 were reduced and fixed via the minimally invasive approach (closed reduction and internal fixation by intramedullary nail). Stratified by the type of internal fixation, 5/18 intertrochanteric fractures were treated by the use of a dynamic hip screw (DHS), 9/18 intertrochanteric fractures were treated by intramedullary nail, and 4/18 intertrochanteric fractures were treated by plate and screws (Table 2 ).

\section{Prognosis}

One elderly (87 years) female patient had pulmonary disease and died at 24 days postoperatively because of uncontrollable pulmonary infection (therefore, we excluded this patient from our cohort when analyzing the prognosis and its influencing factors). In other patients, fractures all achieved bony healing.

The average visual analog score and Harris score at final follow-up (or before arthroplasty was recorded for patients who converted to total hip arthroplasty) were $1.71 \pm 2.08$ points and $84.12 \pm 11.72$ points, respectively. There were 12 patients with excellent and good results (Harris score $\geq 80$ points) and 5 patients with fair and poor results (Harris score $<80$ points). The proportion of patients with an excellentgood Harris score was $70.6 \%$. Three patients converted to total hip arthroplasty (THA). The time from initial treatment to THA was 1.8 years, 2.2 years and 2.5 years, for these three patients. The prognosis of the patients is shown in Table 3. 
Three kinds of complications were commonly identified in patients with acetabular fracture and ipsilateral intertrochanteric fracture. Heterotopic ossification (HO) was identified in 6/17 patients. Two cases were classified as Brooker grade 3 , and four cases were classified as Brooker grades 1-2. Ten of 17 patients were found to have signs of posttraumatic arthritis. There was one patient with arthritis of Kellgren-Lawrence grade 3 and 9 patients with arthritis of Kellgren-Lawrence grades 1-2. Avascular necrosis was identified in four patients. Three of these patients converted to THA (Table 3).

Cox regression models were built to further identify the potential risk factors for poor patient outcomes. Univariate Cox regression models revealed that only hip dislocation was a potential risk factor (Table 4). Then, a multivariate Cox regression model was built to identify the independent risk factors. Stepwise regression revealed that only dislocation of the hip was found to be an independent risk factor $(\mathrm{HR}=$ $9.194,95 \% \mathrm{Cl}=1.024-82.515$ ) for poor outcomes of patients (Table 5). The survivorship curve is shown in Fig. 1.

\section{Discussion}

Fractures of the acetabulum result from high-energy trauma and rarely are associated with a proximal femoral fracture[13]. According to the fracture sites of the proximal femur, we divided these injuries into three groups: acetabular fractures with femoral head fractures, femoral neck fractures and intertrochanteric fractures. In this study, similar to acetabular fracture with femoral head (or neck) fracture, almost all patients were victims of high-impact trauma (e.g., a traffic accident or a fall from a tall height). In addition, 6/18 patients also had a dislocated hip joint. Some patients with acetabular fractures present with hip joint dislocations that most commonly result from high-impact trauma and damage to hip joint stability $[14,15]$. This indicates that after causing fractures at two sites around the hip, the impact from the trauma still may not be fully absorbed and may cause the hip joint to be dislocated[7, 16-18]. According to the Evans classification, most intertrochanteric fractures are type 3 or type 4, which are considered unstable[19,20]. The most common type of acetabular fracture is a posterior wall fracture, which has a weaker influence on stress distribution but a stronger influence on the stability of the hip joint $[13,21,22]$.

Because they result from high-impact, intra-articular injuries, acetabular fractures with ipsilateral intertrochanteric fractures always present innate difficulties for surgeons in terms of their management[9, $11,18,23]$. In this study, all patients received surgical treatment. However, instead of an emergency surgery, all patients received their operations several days after injury when he or she was hemodynamically stable and well prepared for surgery. During this period, patients were treated with bone traction. If the fractures were combined with a dislocated hip joint, the patient was not treated with an emergency closed reduction because the continuity of the femur was damaged, thus making closed reduction quite difficult[11]. The reduction of the hip joint was achieved together with the surgical treatment of the fractures. For acetabular fractures, surgical treatment is not always necessary[24-27] because in some cases, fractures are considered stable without displacement, and the fracture has little influence on the weight-bearing function of the hip joint[28-30], such as a small fracture fragment (no 
more than $1 / 3$ of the area of the posterior wall) without displacement on the posterior wall. If the fracture is considered unstable with displacement greater than $2 \mathrm{~mm}$, surgical treatment should be performed to achieve anatomical reduction to avoid the potential incidence of posttraumatic arthritis[31-33]. However, in some situations in which the fracture is comminuted and cannot be anatomically reduced, the fracture fragments are resected to avoid the formation of intra-articular free bodies[34-36]. Reconstruction plates and screws were the most commonly used internal fixation for acetabular fractures. The treatment principle for intertrochanteric fracture combined with an acetabular fracture is similar to an isolated intertrochanteric fracture. Intertrochanteric fractures are generally considered unstable[3, 8]; thus, surgical treatment has been performed in all patients. If a patient received surgical treatment for an acetabular fracture, the intertrochanteric fracture could be treated by the same incision (or with some extension). Otherwise, the intertrochanteric fracture could be treated with a minimally invasive surgical procedure (closed reduction and internal fixation). In the past, dynamic hip screws were commonly used for intertrochanteric fracture fixation, and more recently, intramedullary nails and plates (with screws) have been commonly used. By the surgical or conservative treatment described above, both acetabular and intertrochanteric fractures achieved bony healing in all patients.

However, fracture healing does not always equal a satisfactory prognosis. In this study, the majority $(12 / 17,70.6 \%)$ of patients achieved a satisfactory clinical outcome (excellent-good results, Harris score $\geq 80$ points). However, there were still 5 patients with poor outcomes. Among them, 4 patients had developed avascular necrosis of the femoral head, 3 of whom converted to total hip arthroplasty. For the remaining patient, the Harris score was only 77 points. One patient developed severe posttraumatic arthritis (Kellgren-Lawrence grade 3) in her affected hip joint. It seems that the incidence of complications, especially avascular necrosis, is the main cause of poor clinical outcomes. As we know, an isolated acetabular fracture might cause avascular necrosis of the femoral head, but the incidence rate is relatively low[29,37]. In a recent study[12], the incidence of avascular necrosis was $5.6 \%$ after traumatic acetabular fracture. When combined with proximal femoral fractures, the incidence rate of avascular necrosis might increase[13,38]. It has been reported that when an acetabular fracture is identified in a patient, a combined femoral head fracture or femoral neck fracture usually indicates a greater possibility of avascular necrosis and nonunion[4, 6]. However, unlike these two kinds of fractures, an isolated intertrochanteric fracture rarely causes avascular necrosis. This kind of extracapsular fracture has only a limited effect on the blood supply of the femoral head[19]. However, in this study, avascular necrosis was identified in 4/17 patients. We also found that dislocation of the hip joint was identified in 3 of these 4 patients. Furthermore, in our Cox regression models, dislocation of the hip joint was the sole independent risk factor for poor outcomes. Although some recent studies have shown that early reduction of the dislocated hip joint was not found to have as favorable an impact in terms of avascular necrosis[1, $13,14]$, it is generally accepted that the rapid reduction of a hip dislocation is important to reduce the likelihood of avascular necrosis[3]. This case series indicated that delayed reduction might be a potential cause of poor outcomes. In addition, we found that most cases of avascular necrosis are identified within 3 years after the injury. 
We have several limitations in this study. First, this is a retrospective study with a small sample size, which may not have accounted for some important information and potential risk factors. Second, with serious injuries such as the fractures examined herein, patients often have additional injuries, but we did not account for any additional injuries in the analysis. Third, we found that hip dislocation was an independent risk factor for poor patient outcomes. However, all cases of dislocation of the hip joint were reduced several days after injury; thus, we cannot analyze whether an early reduction could be helpful in reducing the incidence of avascular necrosis and further improving the prognosis of patients.

\section{Conclusions}

The detailed characteristics of patients with acetabular fracture and ipsilateral intertrochanteric fracture were identified in this study. Patients with this kind of rare injury are usually young and middle-aged males. High-impact trauma (e.g., traffic accidents or falls from a tall height) is the common cause of injury. For patients undergoing surgical treatment, fracture healing is usually achieved. However, the occurrence of complications, especially avascular necrosis, is the major cause of poor prognosis. Dislocation of the hip joint at the time of injury is considered to be an important risk factor for poor prognosis.

\section{Abbreviations}

ORIF, open reduction and internal fixation; CRIF, closed reduction and internal fixation; VAS, visual analog score; THA, total hip arthroplasty; DHS, dynamic hip screw; HO, heterotopic ossification; HR, hazard ratio; $\mathrm{Cl}$, confidence interval

\section{Declarations}

Ethics approval and consent to participate

This study was approved by the Institutional Review Board of the Third Hospital of Hebei Medical University (No. K20190031) and was conducted in accordance with the Declaration of Helsinki. As this was a retrospective study and all patient information was deidentified before analysis, informed consent was only required for patients whose radiological images would be published.

Consent for publication

Written informed consent was obtained from participants whose radiological data have been published in the journal.

Availability of data and materials

All data generated or analyzed during this study are included in this published article.

Competing interests 
All the authors declare that they have no conflict of interest with any organization that sponsored the research.

\section{Funding}

The study was funded in part by the Nature Science Foundation of Hebei, China (Grant no. H2019206609).

Authors' contributions

All authors have read and approved the manuscript.

Conceptualization: Bo Liu, Yongtai Han.

Data curation: Bo Liu, Wenhui Ma, Sikai Liu, Huijie Li.

Methodology: Bo Liu, Xiao Chen, Wenhui Ma, Mengnan Li, Huijie Li.

Writing: Bo Liu, Sikai Liu, Jia Huo, Yongtai Han.

Acknowledgments

Not applicable

\section{References}

1. Ahmed M, Abuodeh Y, Alhammoud A, Salameh M, Hasan K, Ahmed G. Epidemiology of acetabular fractures in Qatar. Int Orthop. 2018;42(9):2211-7. doi: 10.1007/s00264-018-3824-z.

2. Zyman Corenstein J, Martinez Del Campo Sanchez A. [Acetabulum fractures in the Mexican population]. Acta Ortop Mex. 2018;32(5):251-6.

3. Pascarella R, Fantasia R, Sangiovanni P, Maresca A, Massetti D, Politano R, Cerbasi S. Traumatic hip fracture-dislocation: A middle-term follow up study and a proposal of new classification system of hip joint associated injury. Injury. 2019. doi: 10.1016/j.injury.2019.01.011.

4. Duygulu F, Calis M, Argun M, Guney A. Unusual combination of femoral head dislocation associated acetabular fracture with ipsilateral neck and shaft fractures: A case report. J Trauma. 2006;61(6):1545-8. doi: 10.1097/01.ta.0000224898.83708.e1.

5. Lasanianos N, Kanakaris N, Giannoudis PV. An occult acetabular fracture preceding a femoral neck fracture. Orthopedics. 2009;32(8). doi: 10.3928/01477447-20090624-28.

6. Mann CF, Rebollo MI. Femoral neck fracture complicating a missed acetabular fracture in an elderly patient. Injury. 1998;29(1):75-6.

7. Marchionatti E, Fecteau G, Desrochers A. Traumatic conditions of the coxofemoral joint: luxation, femoral head-neck fracture, acetabular fracture. Vet Clin North Am Food Anim Pract. 2014;30(1):247- 
64, vii. doi: 10.1016/j.cvfa.2013.11.001.

8. Noda M, Takahashi M, Nukuto K, Fujita M, Shinohara I, Suda Y, Ohsawa S. Innovative technique of minimally invasive closed reduction for impacted femoral neck fractures (MICRIF). J Orthop Surg (Hong Kong). 2019;27(1):2309499019832418. doi: 10.1177/2309499019832418.

9. Kuhn KM, Boudreau JA, Watson JT. Rare combination of ipsilateral acetabular fracture-dislocation and pertrochanteric fracture. Am J Orthop (Belle Mead NJ). 2013;42(8):372-5.

10. Barrett MO, Anglen JO, Hoernschemeyer DG, Schnetzler KA. Case report: associated both-column acetabulum fracture with an ipsilateral centrally dislocated intertrochanteric femur fracture. J Trauma. 2009;66(3):918-21. doi: 10.1097/01.ta.0000224118.24154.39.

11. Browne RS, Mullan GB. Intertrochanteric fracture of the femur with ipsilateral central fracture of the acetabulum. Injury. 1980;11(3):251-3.

12. Ziran N, Soles GLS, Matta JM. Outcomes after surgical treatment of acetabular fractures: a review. Patient Saf Surg. 2019;13:16. doi: 10.1186/s13037-019-0196-2.

13. Alonso JE, Volgas DA, Giordano V, Stannard JP. A review of the treatment of hip dislocations associated with acetabular fractures. Clin Orthop Relat Res. 2000(377):32-43.

14. Beebe MJ, Bauer JM, Mir HR. Treatment of Hip Dislocations and Associated Injuries: Current State of Care. Orthop Clin North Am. 2016;47(3):527-49. doi: 10.1016/j.ocl.2016.02.002.

15. Cai L, Lou Y, Guo X, Wang J. Surgical treatment of unstable pelvic fractures with concomitant acetabular fractures. Int Orthop. 2017;41(9):1803-11. doi: 10.1007/s00264-017-3532-0.

16. Tiziani S, Osterhoff G, Campagna JF, Werner CML. Correlation of radiographic variables to guide safe implant positioning during acetabular surgery and hip replacement: a retrospective observational study. Patient Saf Surg. 2019;13:13. doi: 10.1186/s13037-019-0192-6.

17. Braun BJ, Wrona J, Veith NT, Rollman M, Orth M, Herath SC, Holstein JH, Pohlemann T. Predictive value of clinical scoring and simplified gait analysis for acetabulum fractures. J Surg Res. 2016;206(2):405-10. doi: 10.1016/j.jss.2016.08.061.

18. Frascone RJ, Salzman JG, Adams AB, Bliss P, Wewerka SS, Dries DJ. Evaluation of intraosseous pressure in a hypovolemic animal model. J Surg Res. 2015;193(1):383-90. doi: 10.1016/j.jss.2014.07.007.

19. Omari A, Madsen CM, Lauritzen JB, Jorgensen HL, Vojdeman FJ. Comorbidity and mortality after hip fracture in nineteen thousand six hundred and eighty two patients aged eighteen to sixty five years in Denmark from 1996 to 2012. Int Orthop. 2019. doi: 10.1007/s00264-019-04323-z.

20. Xu P, Wang H, Liu ZY, Mu WD, Xu SH, Wang LB, Chen C, Cavanaugh JM. An evaluation of threedimensional image-guided technologies in percutaneous pelvic and acetabular lag screw placement. J Surg Res. 2013;185(1):338-46. doi: 10.1016/j.jss.2013.05.074.

21. Zhuang Y, Zhang K, Wang H, Wei X, Liu P, Wang PF, Cong YX, Lei JL, Kandemir U. A short buttress plate fixation of posterior column through single ilioinguinal approach for complex acetabular fractures. Int Orthop. 2017;41(1):165-71. doi: 10.1007/s00264-016-3225-0. 
22. Wu X. A biomechanical comparison of different fixation techniques for fractures of the acetabular posterior wall. Int Orthop. 2018;42(3):673-9. doi: 10.1007/s00264-017-3728-3.

23. Chen J, Zhang D, Zhang T, Chen C, Song Y, Liu S, Su Y, Guo S. Effect of the vascularized bone components on the survival of vascularized composite allografts. J Surg Res. 2018;224:132-8. doi: 10.1016/j.jss.2017.03.050.

24. Boelch SP, Jordan MC, Meffert RH, Jansen H. Comparison of open reduction and internal fixation and primary total hip replacement for osteoporotic acetabular fractures: a retrospective clinical study. Int Orthop. 2017;41(9):1831-7. doi: 10.1007/s00264-016-3260-x.

25. Askam B, Sims S. Supplemental Superior Buttress Plating for the Treatment of Posterosuperior Wall Acetabulum Fractures. J Orthop Trauma. 2019;33 Suppl 2:S27-s31. doi:

10.1097/bot. 0000000000001394 .

26. Chen J, Liu H, Wang C, Lin X, Gu C, Fan S. Internal fixation of acetabular fractures in an older population using the lateral-rectus approach: short-term outcomes of a retrospective study. $\mathrm{J}$ Orthop Surg Res. 2019;14(1):4. doi: 10.1186/s13018-018-1039-z.

27. He C, Feng JM, Yang QM, Wang Y, Liu ZH. Results of selective hip arthroplasty revision in isolated acetabular failure. J Surg Res. 2010;164(2):228-33. doi: 10.1016/j.jss.2009.06.023.

28. Eastman JG, Fennessy JH, Deafenbaugh B, Chip Routt ML, Jr. Cortical Impaction in Posterior Wall Acetabular Fractures. J Orthop Trauma. 2019. doi: 10.1097/bot.0000000000001427.

29. Garcia-Rey E, Sirianni R, Garcia-Cimbrelo E, Sedel L. Total hip arthroplasty after acetabular fracture: does initial treatment make any difference to the outcome? A 5- to 23-year follow-up with clinical and radiological analysis. Hip Int. 2019:1120700019836413. doi: 10.1177/1120700019836413.

30. Ma W, Zhang X, Wang J, Zhang Q, Chen W, Zhang Y. Optimized design for a novel acetabular component with three wings. A study of finite element analysis. J Surg Res. 2013;179(1):78-86. doi: 10.1016/j.jss.2012.08.036.

31. Giunta JC, Tronc C, Kerschbaumer G, Milaire M, Ruatti S, Tonetti J, Boudissa M. Outcomes of acetabular fractures in the elderly: a five year retrospective study of twenty seven patients with primary total hip replacement. Int Orthop. 2018. doi: 10.1007/s00264-018-4204-4.

32. Hsu CL, Chou YC, Li YT, Chen JE, Hung CC, Wu CC, Shen HC, Yeh TT. Pre-operative virtual simulation and three-dimensional printing techniques for the surgical management of acetabular fractures. Int Orthop. 2018. doi: 10.1007/s00264-018-4111-8.

33. Kashyap S, Mahajan S, Lal M. Effects of topical tranexamic acid during open reduction and internal fixation of acetabular fractures: A retrospective study. Acta Orthop Traumatol Turc. 2019. doi: 10.1016/j.aott.2019.03.006.

34. Kilinc CY, Acan AE, Gultac E, Kilinc RM, Hapa O, Aydogan NH. Treatment results for acetabulum fractures using the modified Stoppa approach. Acta Orthop Traumatol Turc. 2019;53(1):6-14. doi: 10.1016/j.aott.2018.11.003.

35. Zhao DW, Yu XB. Core decompression treatment of early-stage osteonecrosis of femoral head resulted from venous stasis or artery blood supply insufficiency. J Surg Res. 2015;194(2):614-21. doi: 
10.1016/j.jss.2014.12.007.

36. Zhao X, Yan YB, Cao PC, Ma YS, Wu ZX, Zhang Y, Zang Y, Jie Q, Lei W. Surgical results of developmental dysplasia of the hip in older children based on using three-dimensional computed tomography. J Surg Res. 2014;189(2):268-73. doi: 10.1016/j.jss.2014.03.003.

37. Stewart RG, Hammer N, Kieser DC. External fixation of unstable pelvic fractures: a systematic review and meta-analysis. ANZ J Surg. 2019. doi: 10.1111/ans.15027.

38. Ingle M, Bhalotia A, Chandele V. Bilateral Anterior Column Acetabulum Fracture following Road Traffic Accident: A Rare Presentation. J Orthop Case Rep. 2018;8(5):72-4. doi: 10.13107/jocr.22500685.1218.

\section{Tables}

Table 1. General information and fracture classification of patients

\begin{tabular}{|c|c|c|c|c|c|c|c|c|c|}
\hline Case & $\begin{array}{l}\text { Age } \\
\text { (years) }\end{array}$ & Gender & Side & Etiology & $\begin{array}{l}\text { Dislocation } \\
\text { of hip }\end{array}$ & $\begin{array}{l}\text { Time to } \\
\text { surgery } \\
\text { (days) }\end{array}$ & $\begin{array}{l}\text { Evans classification for } \\
\text { intertrochanteric } \\
\text { fracture }\end{array}$ & $\begin{array}{l}\text { Letournel classification } \\
\text { for acetabular fracture }\end{array}$ & $\begin{array}{l}\text { Follow-up } \\
\text { time } \\
\text { (years) }\end{array}$ \\
\hline 1 & 49 & Male & Right & $\begin{array}{l}\text { Crushing } \\
\text { Injury }\end{array}$ & No & 8 & 4 & 1 & 16.0 \\
\hline 2 & 46 & Male & Left & $\begin{array}{l}\text { Crushing } \\
\text { Injury }\end{array}$ & No & 14 & 3 & 7 & 15.7 \\
\hline 3 & 46 & Male & Right & $\begin{array}{l}\text { Fall from } \\
\text { a tall } \\
\text { height }\end{array}$ & No & 8 & 3 & 4 & 15.4 \\
\hline 4 & 31 & Female & Right & $\begin{array}{l}\text { Crushing } \\
\text { Injury }\end{array}$ & Yes & 3 & 3 & 4 & 13.6 \\
\hline 5 & 26 & Male & Left & $\begin{array}{l}\text { Traffic } \\
\text { accident }\end{array}$ & No & 5 & 3 & 1 & 12.0 \\
\hline 6 & 42 & Male & Right & $\begin{array}{l}\text { Fall from } \\
\text { a tall } \\
\text { height }\end{array}$ & No & 4 & 3 & 1 & 11.4 \\
\hline 7 & 25 & Female & Left & $\begin{array}{l}\text { Traffic } \\
\text { accident }\end{array}$ & Yes & 12 & 3 & 1 & 10.0 \\
\hline 8 & 69 & Male & Left & $\begin{array}{l}\text { Traffic } \\
\text { accident }\end{array}$ & No & 6 & 3 & 1 & 9.5 \\
\hline 9 & 87 & Female & Left & $\begin{array}{l}\text { Slip, trip, } \\
\text { or fall }\end{array}$ & No & 15 & 3 & 1 & - \\
\hline 10 & 47 & Male & Right & $\begin{array}{l}\text { Traffic } \\
\text { accident }\end{array}$ & No & 5 & 4 & 1 & 9.3 \\
\hline 11 & 22 & Male & Right & $\begin{array}{l}\text { Traffic } \\
\text { accident }\end{array}$ & Yes & 5 & 3 & 7 & 7.8 \\
\hline 12 & 47 & Male & Left & $\begin{array}{l}\text { Traffic } \\
\text { accident }\end{array}$ & Yes & 8 & 4 & 1 & 8.0 \\
\hline 13 & 42 & Male & Left & $\begin{array}{l}\text { Traffic } \\
\text { accident }\end{array}$ & No & 6 & 2 & 1 & 7.7 \\
\hline 14 & 39 & Male & Right & $\begin{array}{l}\text { Traffic } \\
\text { accident }\end{array}$ & Yes & 4 & 3 & 1 & 7.8 \\
\hline 15 & 16 & Male & Left & $\begin{array}{l}\text { Traffic } \\
\text { accident }\end{array}$ & No & 4 & 4 & 2 & 7.2 \\
\hline 16 & 43 & Male & Right & $\begin{array}{l}\text { Traffic } \\
\text { accident }\end{array}$ & No & 15 & 3 & 1 & 6.6 \\
\hline 17 & 28 & Male & Right & $\begin{array}{l}\text { Fall from } \\
\text { a tall } \\
\text { height }\end{array}$ & Yes & 12 & 3 & 1 & 6.4 \\
\hline 18 & 65 & Male & Right & $\begin{array}{l}\text { Fall from } \\
\text { a tall } \\
\text { height }\end{array}$ & No & 23 & 3 & 4 & 6.2 \\
\hline
\end{tabular}


Note: The patient in case 9 died because of pulmonary infection after operation.

Table 2. Treatment methods of patients.

\begin{tabular}{|c|c|c|c|c|c|c|c|c|c|}
\hline \multirow{3}{*}{$\begin{array}{l}\text { Case } \\
1\end{array}$} & \multicolumn{4}{|c|}{ Acetabular fracture } & \multicolumn{5}{|c|}{ Intertrochanteric fracture } \\
\hline & \multirow{2}{*}{$\begin{array}{l}\text { Treatment } \\
\text { ORIF }\end{array}$} & \multirow{2}{*}{$\begin{array}{l}\text { Approach } \\
\text { Kocher-Langenbeck }\end{array}$} & \multicolumn{2}{|c|}{ Internal fixation } & \multirow{2}{*}{$\begin{array}{l}\text { Treatment } \\
\text { ORIF }\end{array}$} & \multicolumn{3}{|c|}{ Approach } & \multirow{2}{*}{$\begin{array}{l}\text { Internal fixation } \\
\text { DHS }\end{array}$} \\
\hline & & & Screws & & & $\begin{array}{l}\text { Same incision } \\
\text { fracture }\end{array}$ & for & acetabular & \\
\hline 2 & ORIF & Kocher-Langenbeck & $\begin{array}{l}\text { Plate } \\
\text { screws }\end{array}$ & with & ORIF & $\begin{array}{l}\text { Same incision } \\
\text { fracture }\end{array}$ & for & acetabular & DHS \\
\hline 3 & Conservative & - & - & & ORIF & Lateral approach & & & DHS \\
\hline 4 & ORIF & $\begin{array}{l}\text { Ilioinguinal } \\
\text { approach }\end{array}$ & $\begin{array}{l}\text { Plate } \\
\text { screws }\end{array}$ & with & ORIF & $\begin{array}{l}\text { Same incision } \\
\text { fracture }\end{array}$ & for & acetabular & DHS \\
\hline 5 & Conservative & - & - & & ORIF & Lateral approach & & & $\begin{array}{l}\text { Intramedullary } \\
\text { nail }\end{array}$ \\
\hline 6 & ORIF & Watson-Jones & $\begin{array}{l}\text { Plate } \\
\text { screws }\end{array}$ & with & ORIF & $\begin{array}{l}\text { Same incision } \\
\text { fracture }\end{array}$ & for & acetabular & DHS \\
\hline 7 & ORIF & Kocher-Langenbeck & Screws & & ORIF & $\begin{array}{l}\text { Same incision } \\
\text { fracture }\end{array}$ & for & acetabular & Plate with screws \\
\hline 8 & Conservative & - & - & & CRIF & - & & & $\begin{array}{l}\text { Intramedullary } \\
\text { nail }\end{array}$ \\
\hline 9 & Conservative & - & - & & CRIF & - & & & $\begin{array}{l}\text { Intramedullary } \\
\text { nail }\end{array}$ \\
\hline 10 & ORIF & Kocher-Langenbeck & $\begin{array}{l}\text { Plate } \\
\text { screws }\end{array}$ & with & ORIF & $\begin{array}{l}\text { Same incision } \\
\text { fracture }\end{array}$ & for & acetabular & $\begin{array}{l}\text { Intramedullary } \\
\text { nail }\end{array}$ \\
\hline 11 & ORIF & Kocher-Langenbeck & $\begin{array}{l}\text { Plate } \\
\text { screws }\end{array}$ & with & ORIF & $\begin{array}{l}\text { Same incision } \\
\text { fracture }\end{array}$ & for & acetabular & Plate with screws \\
\hline 12 & Resection & Kocher-Langenbeck & - & & ORIF & $\begin{array}{l}\text { Same incision } \\
\text { fracture }\end{array}$ & for & acetabular & $\begin{array}{l}\text { Intramedullary } \\
\text { nail }\end{array}$ \\
\hline 13 & Conservative & $\cos 2 \cos 20$ & - & & CRIF & 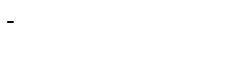 & & & $\begin{array}{l}\text { Intramedullary } \\
\text { nail }\end{array}$ \\
\hline 14 & ORIF & Kocher-Langenbeck & $\begin{array}{l}\text { Plate } \\
\text { screws }\end{array}$ & with & ORIF & $\begin{array}{l}\text { Same incision } \\
\text { fracture }\end{array}$ & for & acetabular & Plate with screws \\
\hline 15 & ORIF & Kocher-Langenbeck & $\begin{array}{l}\text { Plate } \\
\text { screws }\end{array}$ & with & ORIF & $\begin{array}{l}\text { Same incision } \\
\text { fracture }\end{array}$ & for & acetabular & $\begin{array}{l}\text { Intramedullary } \\
\text { nail }\end{array}$ \\
\hline 16 & Resection & Smith-Peterson & - & & ORIF & $\begin{array}{l}\text { Same incision } \\
\text { fracture }\end{array}$ & for & acetabular & $\begin{array}{l}\text { Intramedullary } \\
\text { nail }\end{array}$ \\
\hline 17 & ORIF & Kocher-Langenbeck & Screws & & ORIF & $\begin{array}{l}\text { Same incision } \\
\text { fracture }\end{array}$ & for & acetabular & Plate with screws \\
\hline 18 & Conservative & - & - & & CRIF & - & & & $\begin{array}{l}\text { Intramedullary } \\
\text { nail }\end{array}$ \\
\hline
\end{tabular}

ORIF, open reduction and internal fixation; CRIF, closed reduction and internal fixation; DHS, dynamic hip screw

Table 3. Prognosis and complications of patients at final follow-up. 


\begin{tabular}{|c|c|c|c|c|c|c|c|}
\hline Case & $\begin{array}{l}\text { Harris } \\
\text { score }\end{array}$ & $\begin{array}{l}\text { VAS } \\
\text { score }\end{array}$ & $\begin{array}{l}\text { Heterotopic ossification } \\
\text { (Brooker grade) }\end{array}$ & $\begin{array}{l}\text { Posttraumatic arthritis (Kellgren- } \\
\text { Lawrence grade) }\end{array}$ & $\begin{array}{l}\text { Avascular necrosis of } \\
\text { femoral head }\end{array}$ & $\begin{array}{l}\text { Converted } \\
\text { to THA }\end{array}$ & $\begin{array}{l}\text { Time to } \\
\text { THA }\end{array}$ \\
\hline 1 & 92 & 0 & - & 0 & No & No & - \\
\hline 2 & 85 & 1 & - & 1 & No & No & - \\
\hline 3 & 89 & 1 & - & 1 & No & No & - \\
\hline 4 & 91 & 0 & - & 0 & No & No & - \\
\hline 5 & 88 & 0 & - & 0 & No & No & - \\
\hline 6 & 96 & 0 & 3 & 0 & No & No & - \\
\hline 7 & 79 & 4 & - & 3 & No & No & - \\
\hline 8 & 93 & 1 & - & 0 & No & No & - \\
\hline 9 & - & - & - & - & - & - & - \\
\hline 10 & 93 & 0 & 1 & 1 & No & No & - \\
\hline $11^{*}$ & 55 & 5 & - & 1 & Yes & Yes & 2.2 \\
\hline $12^{*}$ & 67 & 6 & 1 & 2 & Yes & Yes & 1.8 \\
\hline 13 & 91 & 0 & - & 0 & No & No & - \\
\hline 14 & 84 & 1 & - & 2 & No & No & - \\
\hline 15 & 96 & 0 & 1 & 0 & No & No & - \\
\hline $16^{*}$ & 66 & 5 & 3 & 1 & Yes & Yes & 2.5 \\
\hline 17 & 77 & 3 & 2 & 1 & Yes & No & - \\
\hline 18 & 88 & 2 & - & 1 & No & No & - \\
\hline
\end{tabular}

Note: The patient in case 9 died because of pulmonary infection after the operation.

VAS, visual analog score; THA, total hip arthroplasty

${ }^{*}$ Last follow-up before total hip arthroplasty

Table 4. Univariate Cox regression models for potential risk factors for poor outcomes of patients.

\begin{tabular}{|c|c|c|c|c|}
\hline Risk factors & & $\mathrm{HR}$ & $95 \% \mathrm{CI}$ & $\mathrm{P}$ \\
\hline Age (years) & & 0.959 & $0.890-1.033$ & 0.269 \\
\hline \multirow[t]{2}{*}{ Gender } & Male (Ref.) & & & \\
\hline & Female & 1.293 & 0.139-11.994 & 0.821 \\
\hline \multirow[t]{2}{*}{ Side } & Left (Ref.) & & & \\
\hline & Right & 1.066 & 0.178-6.399 & 0.994 \\
\hline \multirow[t]{2}{*}{ Etiology } & Traffic accident (Ref.) & & & \\
\hline & Other & 0.234 & $0.025-2.201$ & 0.204 \\
\hline \multirow[t]{2}{*}{ Dislocation of hip } & No (Ref.) & & & \\
\hline & Yes & 9.194 & $1.024-82.515$ & 0.048 \\
\hline Time to surgery (days) & & 1.091 & $0.936-1.270$ & 0.266 \\
\hline \multirow[t]{2}{*}{ Evans classification for intertrochanteric fracture } & 2 or 3(Ref.) & & & \\
\hline & 4 & 1.005 & $0.111-9.057$ & 0.997 \\
\hline \multirow[t]{2}{*}{ Letournel classification for acetabular fracture } & Posterior wall (Ref.) & & & \\
\hline & Other & 0.443 & $0.049-3.987$ & 0.468 \\
\hline \multirow[t]{2}{*}{ Treatment for acetabular fracture } & Conservative or Resection (Ref.) & & & \\
\hline & ORIF & 0.828 & $0.137-5.005$ & 0.837 \\
\hline
\end{tabular}

Note: For patients who converted to total hip arthroplasty, the survival time is the period between the time of fracture occurrence and the time of total hip arthroplasty. Survival events were defined as patients who did not receive total hip arthroplasty, and his/her Harris scorewas more than 80 points at the last follow-up.

HR, hazard ratio; CI, confidence interval; ORIF, open reduction and internal fixation

Table 5. Multivariate Cox regression models for potential risk factors for poor outcomes of patients (only variables in the equation are shown in the table).

\begin{tabular}{lllll}
\hline Risk factors & & HR & 95\% CI & P \\
\hline Dislocation of hip & $\begin{array}{l}\text { No (Ref.) } \\
\text { Yes }\end{array}$ & 9.194 & $1.024-82.515$ & 0.048 \\
\hline
\end{tabular}




\section{Figures}

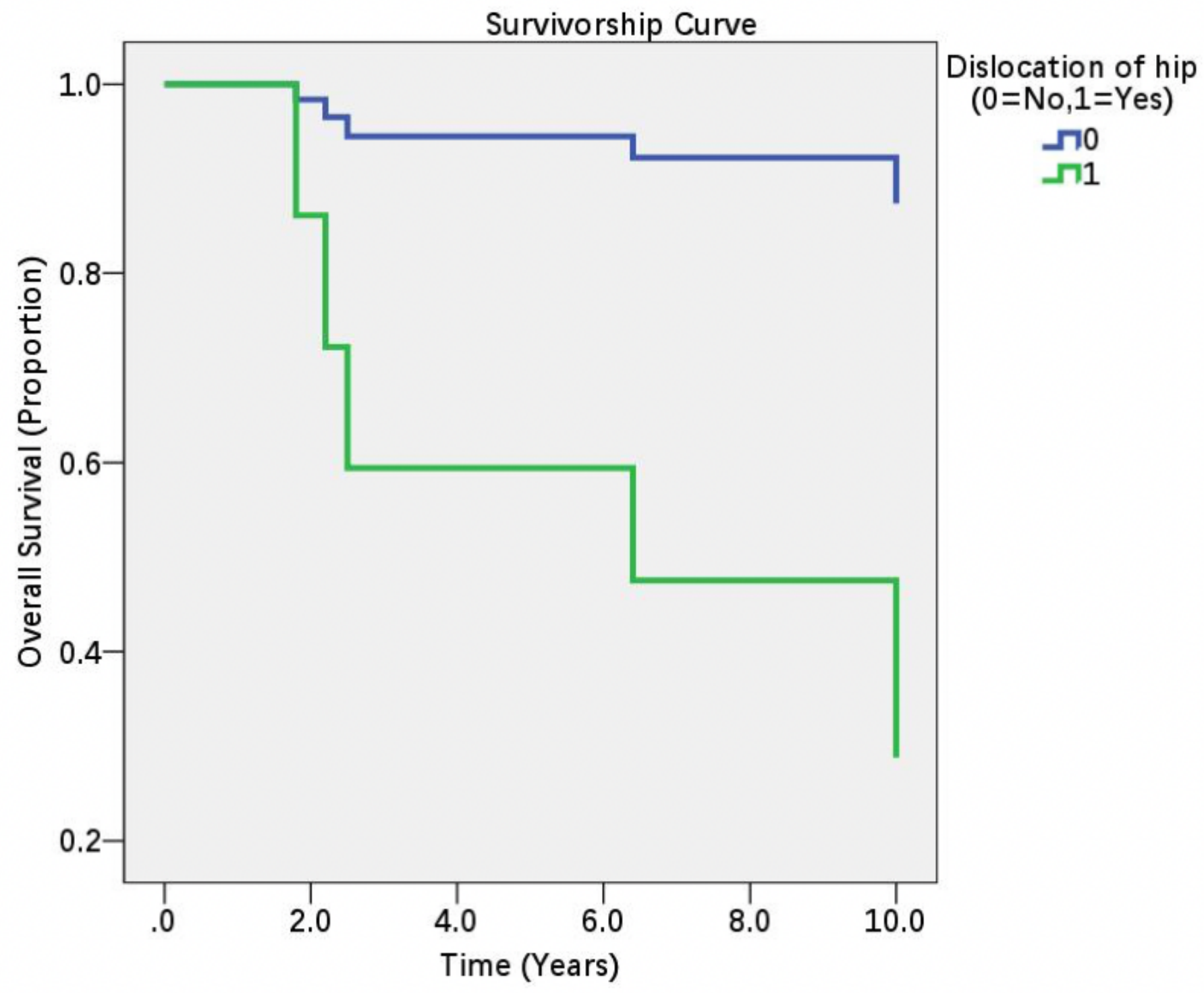

\section{Figure 1}

Survivorship curve for patients with acetabular fracture and ipsilateral intertrochanteric fracture. Note: One elderly (87 years) female patient was excluded from our cohort study because she had a life-long pulmonary disease and died of pulmonary infection 24 days postoperatively. Poor outcome was defined as if the patient had a Harris score less than 80 points or the patient underwent a total hip arthroplasty. 


\section{Figure 2}

(Case 11). A 22-year-old male patient with traumatic acetabular fracture combined with ipsilateral intertrochanteric fracture in his right hip. The patient underwent open reduction and internal fixation surgery for both his acetabulum and proximal femur. Then, 2.2 years after surgery, avascular necrosis of the right femoral head was identified and finally converted to total hip arthroplasty. a-c. computed tomography showed avascular necrosis of the right femoral head $d$. anterior-posterior view before hip arthroplasty e. lateral view before hip arthroplasty $\mathrm{f}$. anterior-posterior view after hip arthroplasty $\mathrm{g}$. lateral view after hip arthroplasty

\section{Figure 3}

(Case 17). A 28-year-old male patient with traumatic acetabular fracture combined with ipsilateral intertrochanteric fracture in his right hip. The patient underwent open reduction and internal fixation surgery for both his acetabulum and proximal femur. An absorbable screw was used to fix the fracture fragment of the posterior wall. Plates and screws were used to fix the intertrochanteric fracture. a-d. computed tomography showed posterior wall fracture of the acetabulum and dislocation of the hip joint e. anterior-posterior view at final follow-up f. lateral view before hip arthroplasty at final follow-up 